\title{
Electric Field and Potential Distribution in a 420 kV Novel Unibody Composite Cross-Arm
}

\author{
Jahangiri, Tohid ${ }^{1}$; Bak, Claus Leth ${ }^{1}$; Faria da Silva, Filipe ${ }^{1}$; Endahl, Brian ${ }^{2}$. \\ ${ }^{1}$ Aalborg University, Denmark, ${ }^{2}$ Bystrup Architecture Design \& Engineering, Denmark
}

\begin{abstract}
The use of uni-body composite cross-arm in a fully composite-based pylon is a new concept for the next generation of overhead transmission lines. The crossarm is stressed by phase-to-phase voltages except in two regions, which are stressed by phase-to-ground voltages caused by installation of shield wires. Due to a major difference between the novel cross-arm structure and traditional composite cross-arms, the electric field distribution in the uni-body composite cross-arm is of considerable interest. This paper presents and analyses the electric field distribution around and inside the hollow core uni-body cross-arm through which ground cable passes to connect the shield wires. Two different shed profiles are considered on the cross-arm and evaluated based on the guidelines of IEC 60815-3.

The 2D geometry of pylon is modeled in ANSYS Finite Element Analysis package. The electric field and potential distribution along the pylon is graphically depicted and the effectiveness of assigned shed profiles in controlling the power frequency stresses are investigated in the areas with high field intensities.
\end{abstract}

\section{Introduction}

Modern day overhead transmission lines are taking a giant leap in modernization, with the change in power generation from fossil fuels to renewable sources such as solar power, hydro power and wind power. The renewable generation needs to be connected to a large scale high-voltage transmission grid. In Europe alone, $28.000 \mathrm{~km}$ of $400 \mathrm{kV}$ transmission line is needed by 2020 to fulfil the aim of providing 20\% of Europe's energy from green energies. It means that more than 100.000 new pylons will be needed [1]. For this reason, the next generation of overhead line is introduced, by developing new design pylons that are easier to erect, less costly, smaller and better looking than the old ones, which is important to get public acceptance.

In this regard, a fully composite-based pylon for $400 \mathrm{kV}$ lines is presented with a new innovative design concept. As it can be seen in Fig. 1, the integration of insulators in cross-arm design with diagonal arrangement of conductors is the prominent feature of the pylon in comparison with conventional towers.

The available scientific work on fully composite pylons is minimum and the traditional insulators' technical standards are not applicable in the design process of the novel cross-arm. Traditional composite insulators produced by manufacturers differ in many aspects such as the figuration of sheds (shed array mode) which play a very important role in their contamination performances [2]. The proper designs of shed profiles are important for [3]:

- Avoiding rain bridging,

- Preventing local short-circuiting between sheds,

- Aiding self-cleaning,

- Avoiding pollution “traps”,

- Controlling local electric field stress.

However, composite insulators with alternating large and small shed designs are commonly used in transmission lines. Conventionally, the selection and dimensioning of insulation for outdoor use has largely been based on creepage distance alone, which is defined according to the "only" minimum requirements presented in IEC 60815-3 [4].

On the other hand, the electric field distribution on composite insulators is more non-linear which is caused by missing intermediate metal parts and by their dielectric material properties [5]. The fully composite pylon is in the most non-linear situation and its electrical performance can only be evaluated numerically e.g. using the Finite Element Method (FEM). Nowadays, Finite Element Method has been recognized as practical and accurate method of field computation to aid in electrical design and has been widely used for the modeling of towers, insulators, conductors, switches, etc. [6]. Electrostatic analysis using FEM allows the designer to engineer different models and variations in the design before high voltage testing, thus saving time and money as the need to manufacture several working prototypes is eradicated [7].

In this paper, a uniform and an alternating large and small shed profile designs are separately assumed for shed housing of the unibody cross-arm. The acceptability of shed designs are verified by evaluation factors reported in IEC/TS 60815-3. Subsequently, three extensive 2D FEM modeling of a fully composite pylon are carried out using the FEM software ANSYS. Using 2D quasi-static time harmonic analysis, the potential and electric field distribution around the pylon and inside the unibody cross-arm is calculated and presented with/without the application of a ground cable inside the hollow cross-arm. Finally, the effectiveness of assigned shed profiles is investigated by considering some criteria regarding to the power frequency stresses constraints on the unibody cross-arm.

\section{Configuration of fully composite pylon}

The novel cross-arm of the fully composite pylon acts 


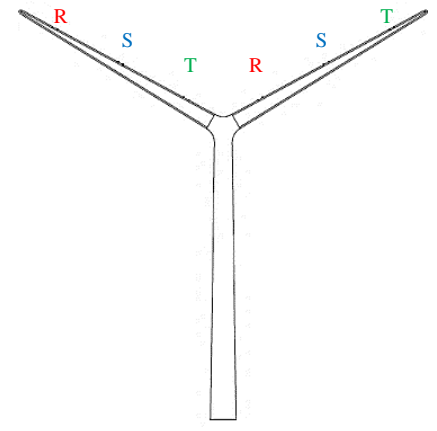

Fig.1: Fully composite pylon with asymmetrical phase arrangements (RST-TSR)

Table I: Minimum required creepage distances on the unibody cross-arm based on IEC/TS 60815-3*

\begin{tabular}{|c|c|c|c|}
\hline $\begin{array}{c}\text { Pollution } \\
\text { Level }\end{array}$ & USCD & $\begin{array}{c}\text { Phase-to- } \\
\text { Phase }\end{array}$ & $\begin{array}{c}\text { Phase-to- } \\
\text { Shield Wire }\end{array}$ \\
\hline (SPS) & $\mathrm{mm} / \mathrm{kV}$ & $\mathrm{mm}$ & $\mathrm{mm}$ \\
\hline C - Medium & 34.7 & 14574 & 8414 \\
\hline
\end{tabular}

as unibody insulator in order to reduce the tower height. The lightning shielding of pylon requires a ground potential access to shield wires which can be achieved by utilizing ground cable inside the hollow cross-arm and pylon body. Considering ground cable, the crosssection of unibody cross-arm is completely exposed to phase-to-ground stresses, due to the interaction between energized parts on the pylon (phase conductors) and ground cable. A hypothetical approach is to eliminate ground cable inside the fully composite pylon, shown in Fig. 1. In this case, the cross-section is no longer exposed to the phase-to-ground voltage and the unibody cross-arm would be stressed by phase-to-phase voltages except two regions which would be stressed by phaseto-ground voltages caused by installation of shield wires (at both tips of cross-arm). Non-conductive conductor clamps on the pylon are ignored for simplification (the worst condition for cross-arm). ACSR Martin conductors are supposed in a twin bundle for each phase on the double circuit $400 \mathrm{kV}$ fully composite pylon. The conductors are placed in a specific height toward the top surface of cross-arm. The pylon dimensions are obtained from [1]. The assumption is that the pylon is under dry and clean conditions and there is no leakage current on the cross-arm surfaces.

\section{Creepage distances and shed profiles}

The minimum required creepage distances on the unibody cross-arm are determined based on the guidelines of [3] for Medium pollution level. Creepage distances on the unibody cross-arm given in Table I, are divided into phase-to-phase and phase-to-ground creepage distances. The creepage distances between two phases as well as between phase and shield wire are provided by sheds. Two shed profile designs are assumed for the insulation of cross-arm; a uniform and an alternating large and small sheds.

According to IEC/TS 60815-3, shed profile of an insula-
Table II: Evaluation of assumed shed parameters based on deviation classes in IEC/TS 60815-3

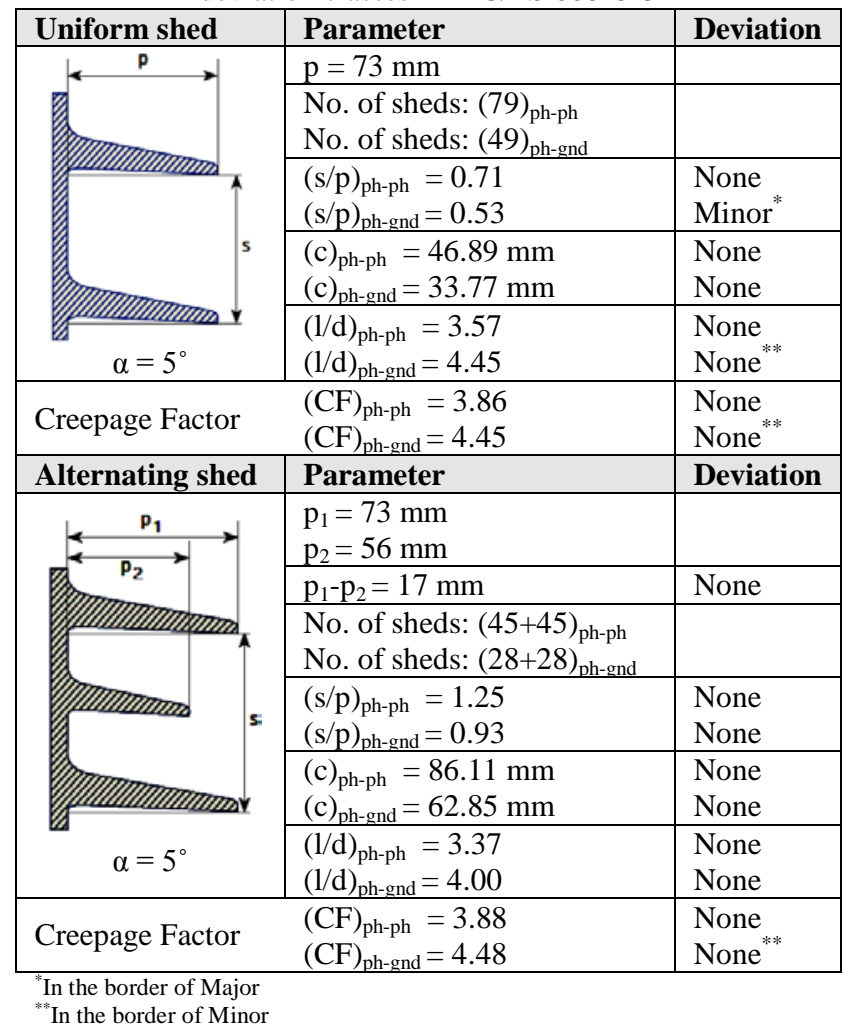

tor is characterized by the following parameters [3]:

- $\quad$ Alternating sheds and shed overhang (p),

- $\quad$ Spacing versus shed overhang (s/p),

- Minimum distance between sheds (c),

- $\quad$ Creepage distance versus clearance (l/d),

- $\quad$ Shed angle $(\alpha)$

Based on how much the parameters can reduce the performance of the insulator, the values of the parameters are categorized in three classes (none, minor, major deviation). The none deviation means that the profile parameter is within a normal range. The minor deviation of parameter can reduce performance and the major deviation can have a serious effect on performance under pollution. IEC/TS 60815-3 recommended that none of the parameters should lie in the 'major deviation' category and preferably with only one in the 'minor deviation' category [8].

The parameters of assumed shed profiles are given in Table II (more details about the parameters of sheds can be found in [3]). From the data of Table II it can be found that, although the assumed values for uniform shed profile are in "None deviation" class except one "Minor" case, three parameters are in the border of deviation. These parameters are related to a region between shield wire and adjacent phase and are as a result of insufficient air clearance in the region. Table II also proves the fact that the alternating shed profiles are applicable for the unibody cross-arm because all parameters are in acceptable and reliable ranges. However, it is necessary to evaluate the effectiveness of assigned shed profiles in terms of controlling the power frequency stresses. 


\section{Set up of 2D finite element model}

ANSYS Parametric Design Language (APDL) is applied in ANSYS for the parametric modeling and analysis of fully composite pylon. Based on the FEM theory, the more fine of mesh, the more precise of results, hence, sufficient element sizes are then employed in the meshing of 2D solid model and subsequently the program generates approximately $1,600,000$ elements. The insulation materials of pylon and corresponding permittivities are chosen as silicone rubber for sheds with $\varepsilon_{\mathrm{r}}=3.7$, fiberglass for cross-arm and pylon body with $\varepsilon_{\mathrm{r}}=5.75$ and polyethylene (PE) for ground cable with $\varepsilon_{\mathrm{r}}=2.3$.

The arrangements of phase conductors on double circuit towers have a significant effect on the levels of electric field around them [9]. The phases' arrangements on the pylon are according to Fig. 1, for taking into account an unsymmetrical loading condition. The potentials of phase conductors are prescribed considering the instantaneous value of highest system voltage, i.e., 420 $\mathrm{kV} / \sqrt{3} \times \sqrt{2} \approx 343 \mathrm{kV}$ applied on phase $\mathrm{R}$ and 343/2 = $171.5 \mathrm{kV}$ applied on other two phases ( $\mathrm{S}$ and $\mathrm{T}$ ). The electric potential of shield wires and copper core of ground cable are set to zero. The line representing the surface of earth is also loaded ground potential. In addition, the far-field boundary of 2D model is modelled with infinite elements.

After completed all of setting, a quasi-static time harmonic analysis in ANSYS is performed for a frequency of $\mathrm{f}=50 \mathrm{~Hz}$. The harmonic electric field analysis produces the directional electric field $\left(\mathrm{EF}_{\mathrm{x}}\right.$ and $\mathrm{EF}_{\mathrm{y}}$ components) and the resultant total electric field at each location where results are reported.

Furthermore, a harmonic analysis in ANSYS assumes that any applied voltages varies harmonically with time [10]. It means that the applied voltages and resulting electric fields are on the complex plane with the real and imaginary components. On the real axis, when one phase has the peak voltage, the other two phases have the negative half peak voltage. Conversely, the phase has a zero value on the imaginary axis while other two phases have $\pm \sqrt{3} / 2$ peak value. The electric field interaction between phase conductors and earthed parts can be evaluated only by considering the resultant magnitude of two components i.e. $\mathrm{EF}_{\mathrm{Re}}$ and $\mathrm{EF}_{\mathrm{Im}}$. On the other hand, the RMS values of electric field can be better interpreted and compared with the electric field constraints which are mentioned in the next section.

\section{Electric field considerations}

The importance of the electric field distribution along a composite insulator has been recognized by the industry [8]. In general, the electrical field stresses on polymeric insulating materials such as silicone rubber shall be as low as possible to avoid tracking and erosion phenomena due to corona discharges. The following criteria are reported as evaluation factors in the design of composite cross-arms:

1) At $0.5 \mathrm{~mm}$ from insulation surface, maximum permissible electric field magnitudes to be less than $0.45 \mathrm{kV}_{\mathrm{RMS}} / \mathrm{mm}[11,8]$.

2) The local field on metal fittings to be below corona inception values $3 \mathrm{kV}_{\mathrm{RMS}} / \mathrm{mm}$ [11], maximum permissible electric field magnitude on metallic endfittings and electric field grading devices: 1.8 $\mathrm{kV}_{\mathrm{RMS}} / \mathrm{mm}$ [8].

3) Maximum permissible electric field magnitude inside the core and sheds (Dielectric materials) to be less than $3 \mathrm{kV}_{\mathrm{RMS}} / \mathrm{mm}[11,8]$.

4) Maximum permissible electric field magnitude at the triple junctions: $0.35 \mathrm{kV}_{\mathrm{RMS}} / \mathrm{mm}$ [8].

Moreover, it is mentioned in [5] that corona discharges at water drop edges may begin to appear already for electrical surface stresses in the range of $0.8 \sim 1.3$ $\mathrm{kV}_{\mathrm{RMS}} / \mathrm{mm}$ but depending also on the hydrophobicity state of the surface. For the purpose of unibody crossarm, criterion 1 and 3 are relevant and essential to be ensured that whether the local peaks of electric field on the cross-arm complies with constraint values. The criterion 2 will be considered, in the future researches, to evaluate the performance of conductor clamps, which are ignored in this study.

\section{Results and discussions}

This section presents and discusses the results of finite element analysis of the fully composite pylon. Three different simulations are carried out in order to evaluate the electric field and potential distribution around and inside the $420 \mathrm{kV}$ unibody cross-arm as follow:

1) Cross-arm with uniform sheds and without ground cable.

2) Cross-arm with uniform sheds and ground cable.

3) Cross-arm with alternate sheds and ground cable.

\subsection{Electric field and potential distribution using uniform sheds without ground cable}

Real component of potential distribution around the fully composite pylon without ground cable is illustrated in Fig. 2, which is influenced by the earth surface and shield wires. Since the circuits of pylon are energized at the same voltage level therefore, the RMS values of electric field are identical at similar points on both sides of cross-arm. For the left circuit of pylon, electric field distribution on the uniform sheds, within fiberglass layer and at $0.5 \mathrm{~mm}$ from insulation surface is shown in Fig. 3 based on targeted axis ranges (The tip of the unibody cross-arm is located at $\mathrm{x}=0$ ). According to Fig. 3-a, local electric field stresses under the lower phase are slightly more than other two phases. It means that the local electric field magnitudes under three phases depend on the height of conductors from the earth surface therefore, the electric field stresses on the cross-arm are predominantly affected by the earth surface. On the other hand, the RMS values of electric field at $0.5 \mathrm{~mm}$ above insulation surface and within 


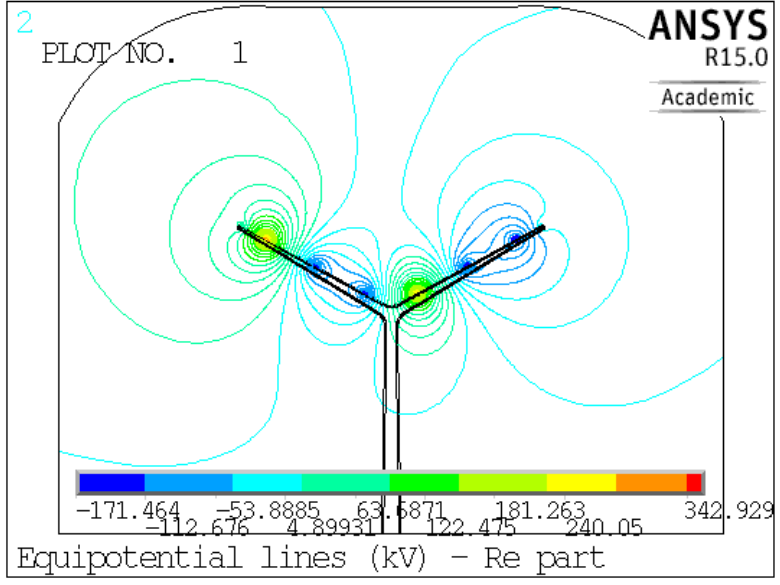

Fig. 2: Equipotential lines around pylon without ground cable

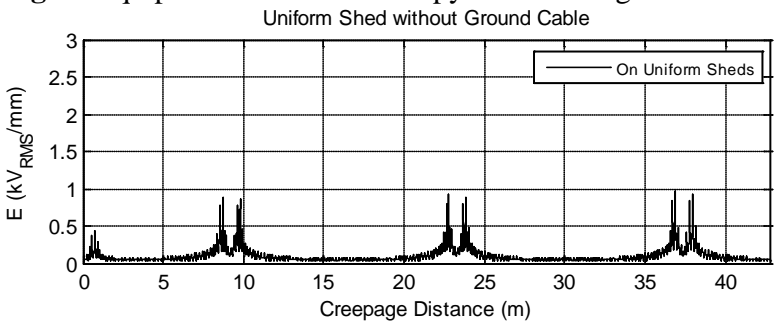

(a)

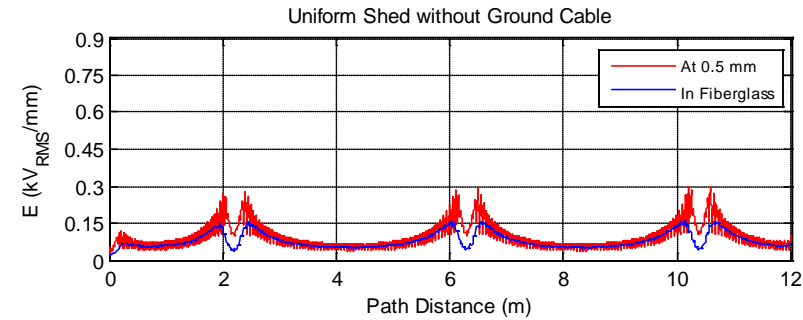

(b)

Fig. 3: Electric field distribution a) on uniform sheds, b) within fiberglass layer and at $0.5 \mathrm{~mm}$ from insulation surface

fiberglass layer and sheds are much lower than the constraint values of 0.45 and $3 \mathrm{kV}_{\mathrm{RMS}} / \mathrm{mm}$, respectively. Consequently, the electrical performance of fully composite pylon without ground cable is of considerable importance and can provide a basis for the next stage in development of composite pylon designs.

\subsection{Electric field and potential distribution using uniform sheds with ground cable}

Real component of potential distribution around the fully composite pylon with ground cable is depicted in Fig. 4 which is mainly affected by ground cable.

Comparing Fig 4 with Fig. 2 demonstrates that potential distribution around the fully composite pylon with/without ground cable depends on the location of ground potential (i.e. earth surface and shield wire or only ground cable).

Considering ground cable inside the pylon, the electric field distribution along the unibody cross-arm is presented in Fig. 5 for the left circuit on the pylon. Initially, comparing Fig. 3 with Fig. 5 shows that utilizing ground cable inside the cross-arm has a serious effect on the electric field magnitudes under the

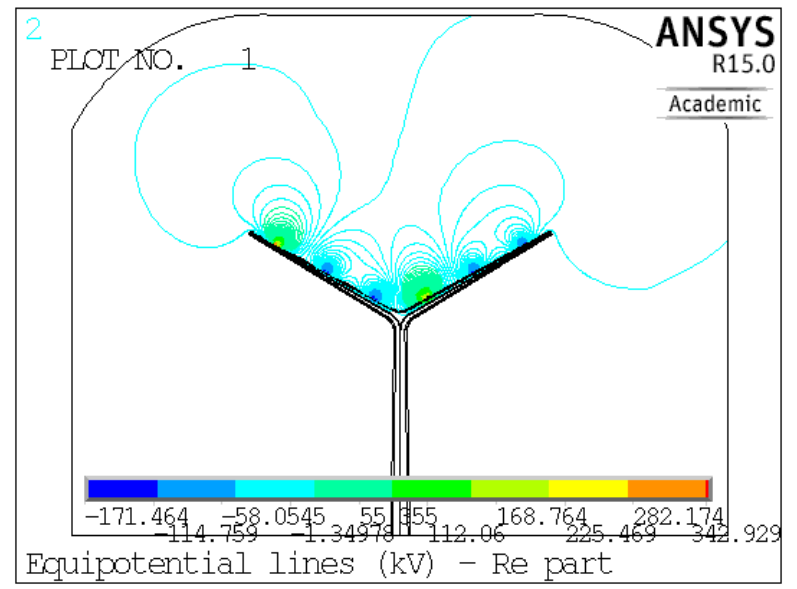

Fig. 4: Equipotential lines around the pylon with ground cable Uniform Shed with Ground Cable

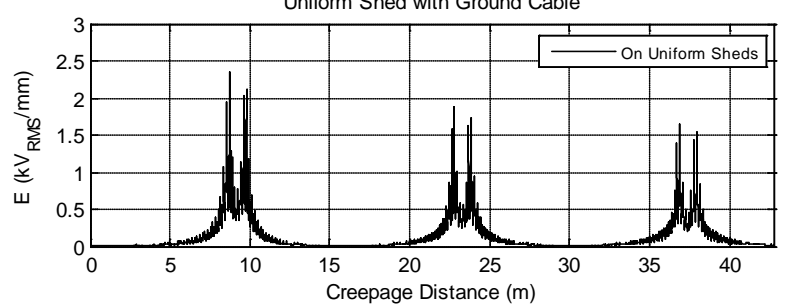

(a)

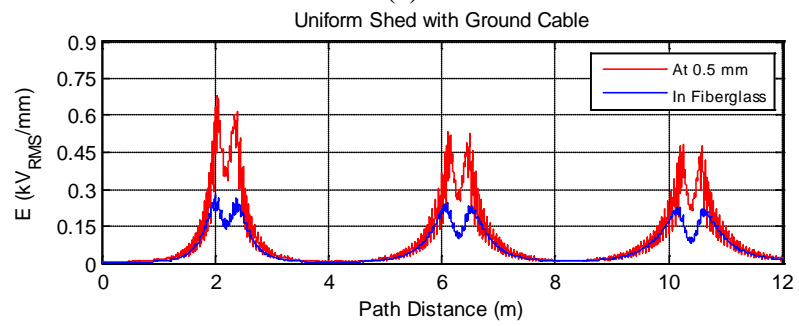

(b)

Fig. 5: Electric field distribution a) on uniform sheds, b) in fiberglass layer and at $0.5 \mathrm{~mm}$ above insulation surface

energized regions. It can also be seen that the peak values of local electric field stresses under the 3 phases of both pylons are in inverse order.

It is due to this fact that the electric field stresses on the pylon without ground cable depend on the height of bundled conductors to earth surface whereas the distance between bundled conductors and ground cable has a large impact on the magnitudes of electric field on the unibody cross-arm. However, the region under the top phase of the pylon with ground cable exposes higher electric field intensities which is caused by the conical shape of cross-arm. For this reason, the electric field distribution cloud chart around the top phase is displayed in Fig. 6 in two specific contour ranges which are relevant to criterion 1 and 3 .

According to Fig. 6-a and Fig. 5-a-b, the highest RMS values of electric field on the uniform sheds and within fiberglass layer are less than the constraint value of 3 $\mathrm{kV}_{\mathrm{RMS}} / \mathrm{mm}$ (criterion 3). Nonetheless, the electric field stresses around the bundled conductors (grey areas) are greater than corona inception value $3 \mathrm{kV}$ RMs $/ \mathrm{mm}$.

The grey areas, shown in Fig. 6-b, implies to the regions which have the RMS value of electric field greater than $0.45 \mathrm{kV}_{\mathrm{RMS}} / \mathrm{mm}$. Under the energized regions (Fig. 6-b 


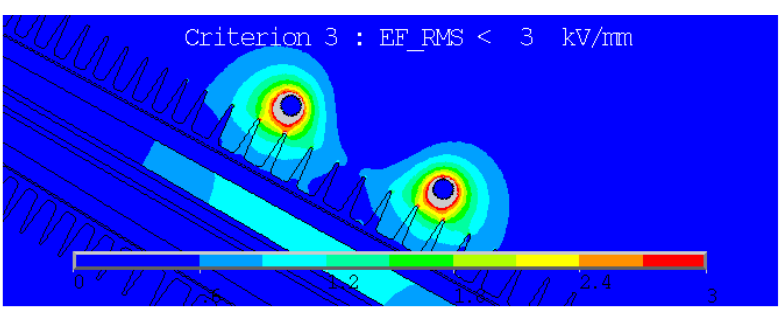

(a)

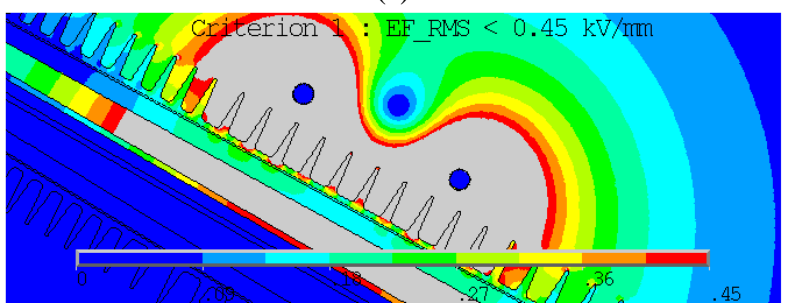

(b)

Fig. 6: Electric field cloud chart around top phase based on a) criterion 3, b) criterion 1

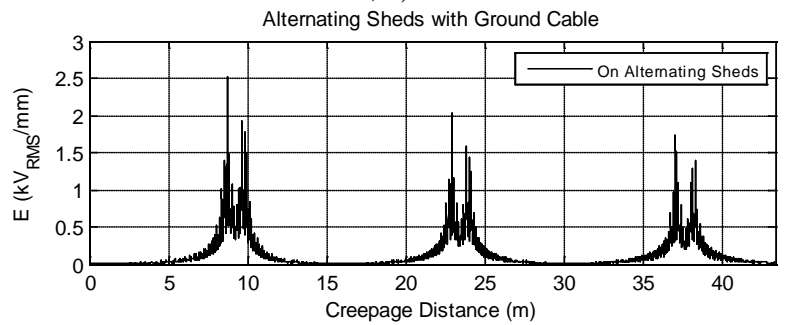

(a)

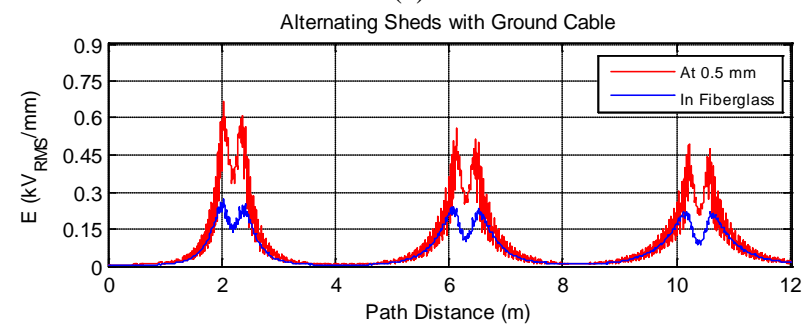

(b)

Fig. 7: Electric field distribution a) on alternating sheds, b) in fiberglass layer and at $0.5 \mathrm{~mm}$ above insulation surface

and Fig. 5-b), electric field magnitudes at $0.5 \mathrm{~mm}$ from insulation surface are higher than the constraint value of $0.45 \mathrm{kV}_{\mathrm{RMS}} / \mathrm{mm}$ (criterion 1). Although the criterion 1 does not fulfil for the pylon with ground cable, there is no concern about the weak point because it is the worst condition on the cross-arm and expected to resolve by the application of non-conductive conductor clamps. Utilizing conductor clamp, the air gap under the bundled conductors will be substituted with a high permittivity dielectric material that improves the electric field stresses around the phase conductors.

\subsection{Electric field and potential distribution using alternating sheds with ground cable}

The effect of shed profiles on the performance of the unibody cross-arm is evaluated in this section by considering ground cable inside the pylon. Fig. 7 shows electric field distribution on the alternating sheds, within fiberglass layer and at $0.5 \mathrm{~mm}$ above insulation surface. Contour plot of electric field is also displayed in Fig. 8

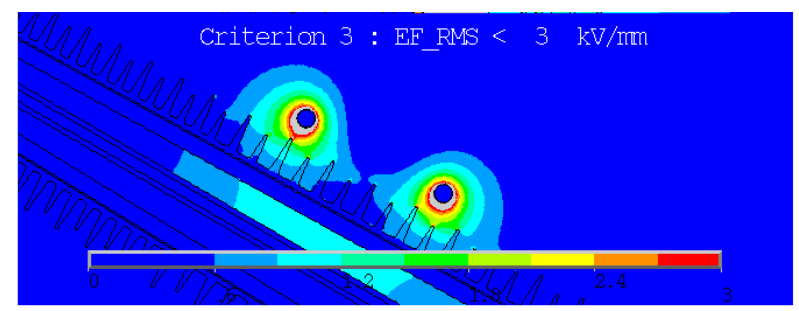

(a)

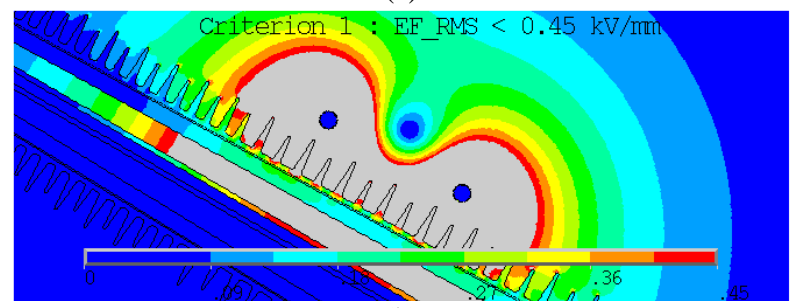

(b)

Fig. 8: Electric field cloud chart around top phase based on a) criterion 3 , b) criterion 1

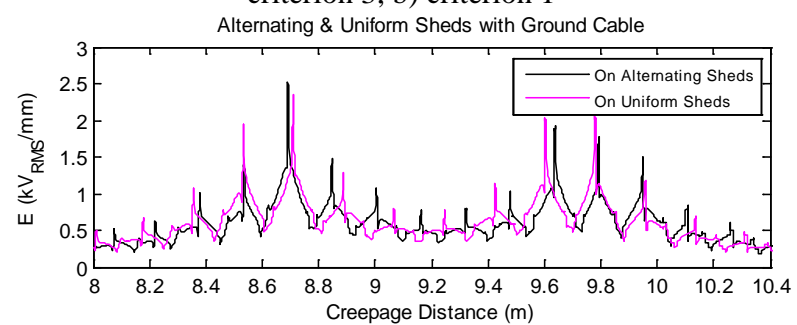

Fig. 9: Electric field magnitudes around top phase

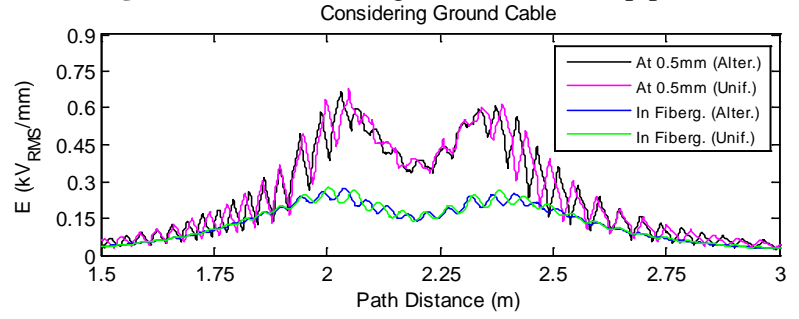

Fig. 10: Electric field magnitudes within fiberglass layer and at $0.5 \mathrm{~mm}$ above insulation surface by considering alternating and uniform sheds

by considering criterion 1 and 3. Fig. 7-a-b and Fig. 8-a demonstrate that the criterion 3 is realized on the alternating sheds and within fiberglass layer. Based on Fig. 7-b and Fig. 8-b, local electric field intensities under phase conductors are still higher than the specified value in criterion 1 which will be resolved using conductor clamps.

In order to compare the effectiveness of uniform and alternating sheds in controlling power frequency stresses, the electric field magnitudes around the top phase conductors are given in Fig. 9 for both types of sheds. Fig. 9 reveals that the electric field magnitudes on the uniform and alternating sheds are approximately at the same levels and there is no significant difference between the performances of two types of sheds.

For both types of shed profiles, the electric field magnitudes within fiberglass layer are in the same levels (Fig. 10). Similarly, the levels of electric field at $0.5 \mathrm{~mm}$ from insulation surface are identical for both types.

As a result, the finite element analyses show that the performances of the assigned uniform and alternating 
sheds are almost identical on the unibody cross-arm. Nonetheless, according to IEC/TS 60815-3 which is the one recommended for use, the assigned alternating large and small shed profiles are more suitable for the fully composite pylon with ground cable.

The reasons for the difference between the results of FEM and IEC standard can be explained as follows:

- FE models are only established for dry and clean environmental conditions whereas IEC/TS 60815-3 practical standard additionally deals with polluted and wet conditions.

- The results of FEA are only interpreted based on some criteria to prevent material degradation while IEC standard takes into account some other considerations such as avoiding shed to shed arcing, avoiding localized pollution build up in deep and narrow sections of shed profile, preventing dry band formation and etc. [3].

This will be studied in more detail in future work.

\section{Conclusions}

In this paper, the electrical performance of fully composite pylon was investigated in controlling the power frequency stresses. Two assumed shed profile designs, uniform and alternating large and small sheds, were evaluated based on IEC/TS 60815-3 guidelines. The IEC evaluation factors verified that the alternating shed profiles are applicable for the insulation of unibody cross-arm, because all shed parameters are in acceptable and reliable ranges. Subsequently, three different 2D finite element analysis of fully composite pylon were carried out in order to evaluate the potential and electric field distribution around and inside the unibody crossarm. Comparing potential distribution around the pylon with/without ground cable showed that the pylon without ground cable is influenced by the earth surface and shield wires, whereas the pylon with ground cable is mainly affected by ground cable.

Based on two criteria, the electric field results along the unibody cross-arm were interpreted in three different paths on the cross-arm: on sheds, within fiberglass layer and at $0.5 \mathrm{~mm}$ above insulation surface. For the pylon with ground cable, electric field magnitudes on uniform and alternating sheds and within fiberglass layer were below the constraint value of $3 \mathrm{kV}_{\mathrm{RMS}} / \mathrm{mm}$. Moreover, there was no significant difference between the performances of both shed profiles.

On the other hand, some local electric field magnitudes at $0.5 \mathrm{~mm}$ from insulation surface were higher than the specified constraint value $\left(0.45 \mathrm{kV}_{\mathrm{RMS}} / \mathrm{mm}\right)$. It was due to the lack of non-conductive conductor clamps for phase conductors and was the worst case for the regions under the energized parts.

By considering IEC recommendations and FE analysis results, it was concluded that using the assigned alternating shed profiles are suitable for the insulation of unibody cross-arm. Furthermore, it is expected that the application of conductor clamps will improve the performance of fully composite pylon with ground cable. Finally, the results of this study provided an important basis on the design of fully composite pylons.

\section{ACKNOWLEDGMENTS}

The authors thank the Danish Research Council (Innovationsfonden) for the financial support of the PoPyFu project.

\section{References}

[1] BYSTRUP - Leading Power Pylon Design, web page: www.powerpylons.com, viewed April 2015.

[2] Zhang Chu-yan, Wang Li-ming, Jia Zhi-dong, and Guan Zhi-cheng, "Research on the Optimization of UHV AC Composite Insulators' Shed", International Conference on High Voltage Engineering and Application (ICHVE), New Orleans, LA, Oct. 2010, pp. 345 - 348.

[3] "IEC/TS 60815-3: Selection and dimensioning of high-voltage insulators intended for use in polluted conditions - Part 3: Polymer insulators for a.c. systems," 2008.

[4] Overhead Lines - A Cigré Green Book. Cigré August 2014.

[5] U. Schümann, F. Barcikowski, M. Schreiber, H. C. Kärner, and J. M. Seifert, "FEM Calculation and Measurement of the Electrical Field Distribution of HV Composite Insulator Arrangements", CIGRE session 2002, 2002, paper 33-404.

[6] Jing Li, Zongren Peng, and Xi Yang, "Potential Calculation and Grading Ring Design for Ceramic Insulators in $1000 \mathrm{kV}$ UHV Substations", IEEE Transactions on Dielectrics and Electrical Insulation, Vol. 19, pp. 723 - 732, 2012.

[7] V. Peesapati, C. Zachariades, Q. Li, S. M. Rowland, I. Cotton, F Allison, D. Chambers, and P. Rhodes, "Electric Field Computation for a 400 kV Composite Cross-Arm", Annual Report Conference on Electrical Insulation and Dielectric Phenomena (CEIDP), Montreal, QC, Oct. 2012, pp. $790-793$.

[8] C. Zachariades, "Development of an Insulating Cross-arm for Overhead Lines", PhD Thesis, School of Electrical and Electronic Engineering, The University of Manchester, 2014.

[9] T. Jahangiri, M. Zavvari, and V. Masouminia, "Effects of catenary, compaction and phase conductor arrangement of double circuit lines on ROW width using calculations and FEM", International Review of Electrical Engineering (IREE), Vol. 7, No. 4, pp. 4980-4991, 2012.

[10] ANSYS User's Manual 15.0, Release 15.0, ANSYS Inc., 2013.

[11] V. Peesapati, C. Zachariades, Q. Li, S. M. Rowland, I. Cotton, P. R. Green, F. Allison, and D. Chambers, "3D Electric Field Computation of a Composite Cross-Arm", IEEE International Symposium on Electrical Insulation (ISEI), San Juan, PR, June 2012, pp. 464 - 468. 